\title{
Semi-Diurnal Tide on the Shelf Break in Northeast of Taiwan
}

\author{
TSWEN YUNG TANG ${ }^{1}$ and DA WEI LEE ${ }^{1}$
}

(Manuscript received 29 July, 1995, in final form 26 January 1996)

\begin{abstract}
On the shelf break in northeast of Taiwan, a buoy-mounted, upward looking Acoustic Doppler Current Profiler (ADCP) was moored at $270 \mathrm{~m}$ to record the current velocity above it. The obtained data was used to study the vertical structure of the semi-diurnal tidal current and its temporal variations. The deployment duration was from September 28 to November 27, 1991 for 59 days. Both barotropic and first baroclinic semi-diurnal tides were found to be important in this area. The nodal point of the first baroclinic tide was located at $110 \mathrm{~m}-130 \mathrm{~m}$. The Kuroshio intrusion, which occurred in midOctober, had a relatively small impact on the barotropic tide but a large one on the baroclinic tide. The speed of the barotropic and baroclinic tides were comparable before the intrusion, but subsequent to the intruded, the baroclinic tide accelerated, and its tidal ellipses showed considerable change in its orientation and eccentricity. In contrast, the difference in barotropic tidal ellipses before and after the intrusion were small.

Changes in local water stratification and background low-frequency current induced by the intrusion of the Kuroshio may have been responsible for the observed variations in the vertical structure of the semi-diurnal tide.
\end{abstract}

(Key words: Barotropic and baroclinic tides, Kuroshio intrusion)

\section{INTRODUCTION}

As part of the Kuroshio Edge Exchange Process (KEEP) program, an upward looking Acoustic Doppler Current Profile: (ADCP) was moored on the shelf break northeast of Taiwan, measuring the ocean current in the upper $240 \mathrm{~m}$ of the water column. Although these measurements were primarily focused toward a study of the vertical structure of lowfrequency current variations (Tang and Yang, 1993), they also enabled an investigation of the semi-diurnal tide on the shelf break. Generally, the semi-diurnal tidal energy on the continental shelf is concentrated in the barotropic and lowest baroclinic modes (Baines, 1986). The baroclinic (or internal) tide on the shelf has been found in many observations, for example, Hayes and Halpern (1976) observed of internal tides and waves off the Oregon Coast.

1 Institute of Oceanography, National Taiwan University, Taipei, Taiwan, R.O.C. 
Further, since the barotropic tide does not convert all of its energy into the baroclinic tide (Wunsch, 1975), it usually remains at a significant amplitude on the shelf. Rosenfeld and Beardsley (1987) and Rosenfeld (1990) found that both barotropic and first baroclinic $M_{2}$ tides are important on the shelf off northern California.

The generation and propagation of an internal tide on the shelf region has been studied using various analytical and numerical models. Zeilon (1912) first suggested that the generation mechanism for internal tides is the interaction of long waves and bottom topography. Subsequent theoretical and numerical model studies are numerous (Rattray et al., 1969; Sandstorm, 1976; Maxworthy, 1979). A general review of the theory and observation of intermal tides in the ocean and on the shelf were given by Wunsch (1975) and Baines (1986), respectively. An internal tide could be generated as a barotropic tide propagating across the bottom topography from the open sea to the continental shelf. The generation process is strongest at or near the shelf break (Baines, 1982), and local water stratification is one crucial factor.

On the continental shelf northeast of Taiwan, Chem and Wang (1990) examined the temperature and salinity vertical profiles over a 24 -hour period and found that the internal semi-diurnal tide amplitude could be as large as $40 \mathrm{~m}$. They inferred that the internal tidal current was a primary source of the vertical water mixing on the shelf. However, the short data records did not allow conclusive results, and many characteristics of the semi-diurnal tide on the shelf region northeast of Taiwan remain a mystery. Accordingly, in the present study, an attempt is made to explore some of these characteristics using current measurements over the water column between $30 \mathrm{~m}$ and $240 \mathrm{~m}$. Special attention is paid to the variation of the semi-diurnal tidal current before and after the Kuroshio intrusion.

The paper proceeds as follows. Section 2 describes the kinematics of the semi-diumal tidal current before and after the Kuroshio intrusion with the total record divided into three segments. A brief review of the background of the low-frequency current, previously described by Tang and Yang (1993), is also given. In Section 3, a coherence analysis is applied to study the vertical structure of the semi-diurnal tidal current and its temporal variation. Section 4 discusses the characteristics of the barotropic and first baroclinic semi-diurnal tides. The separation of these tides is made by assuming that the vertical integration of baroclinic tidal velocity is zero. The potential error due to this assumption and a discussion are provided in Section 5. Section 6 summarizes the finding and presents the conclusions of this paper.

\section{BACKGROUND AND DATA DESCRIPTION}

The mooring location $\left(25^{\circ} 25^{\prime} \mathrm{N}, 122^{\circ} 24^{\prime} \mathrm{E}\right)$ and surrounding bathymetry on the shelf break northeast of Taiwan are shown in Figure 1. The local water depth was $386 \mathrm{~m}$; the ADCP current meter was moored at $270 \mathrm{~m}$, and the current above it was measured. The mooring was deployed for 59 days, from September 28 to November 27, 1991, with samples taken at half-hour intervals. A detailed description of the mooring and data retrieval can be found in Tang and Yang (1993). The acquired data was linearly interpolated from $30 \mathrm{~m}$ to $240 \mathrm{~m}$, and vertical profiles were resampled at fixed $10-\mathrm{m}$ intervals.

Figure 2 shows a stick diagram of the low-pass (36-hour) filtered current velocity at 30 $\mathrm{m}, 80 \mathrm{~m}, 130 \mathrm{~m}, 180 \mathrm{~m}$ and $230 \mathrm{~m}$. The low-pass filtered data was obtained using a truncated Fourier transform to remove those fluctuations shorter than 36 hours from the original time series. A southwest flow dominated over the whole water column, from the beginning of 


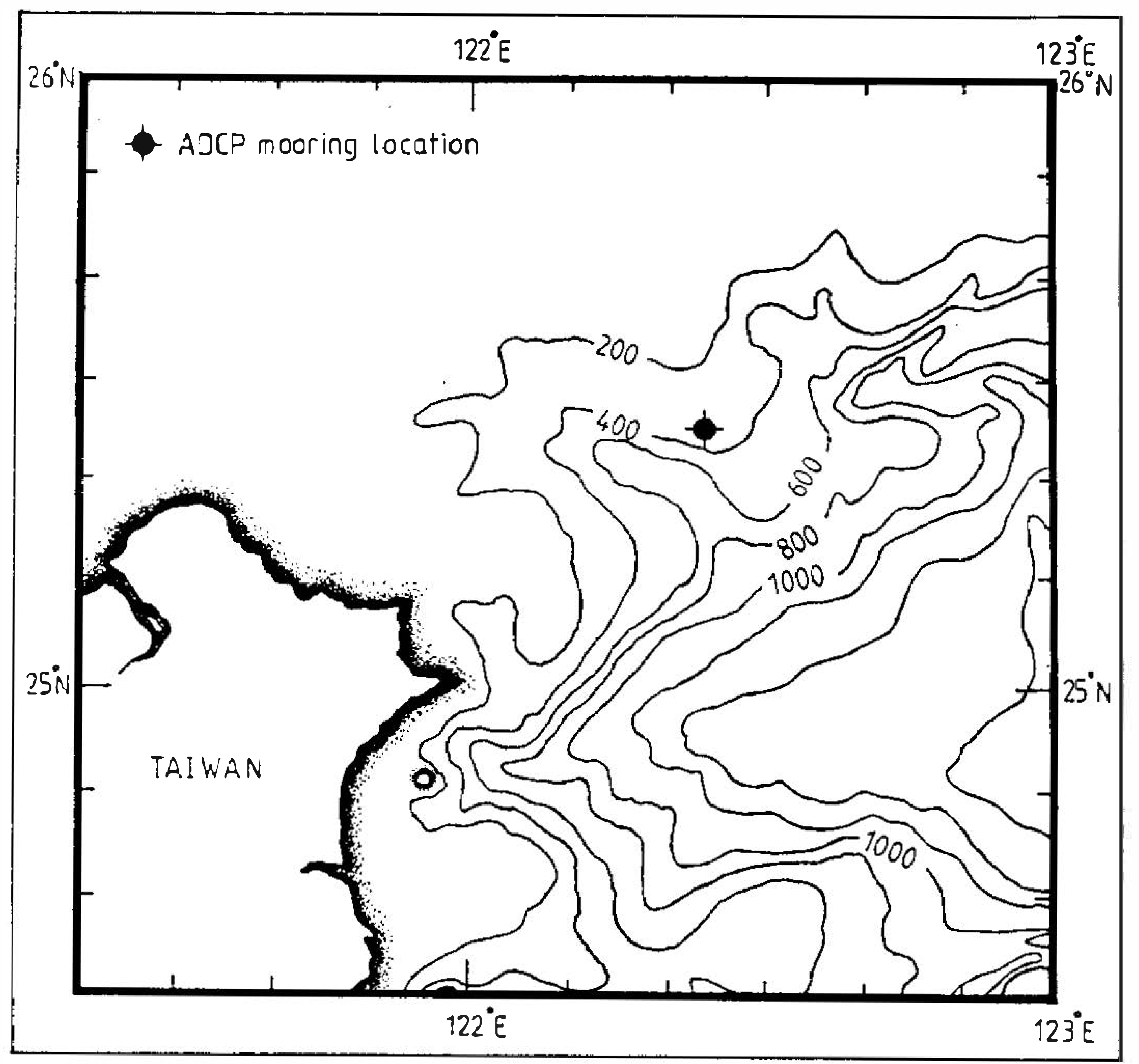

Fig. 1. Mooring location $\left(25^{\circ} 25^{\prime} \mathrm{N}, 122^{\circ} 24^{\prime} \mathrm{E}\right)$ and surrounding bathymetry. Depth contour labels are in meters. (after Tang and Yang, 1993).

the record to mid-October. After which the current abruptly turned northwestwardly. This action initially occurred in the surface layer and then gradually extended to the deeper layer. Below the depth of $170 \mathrm{~m}$, the current resumed its southwest flow. Tang and Yang (1993) concluded that this abrupt change of current direction in the upper ocean was related to the Kuroshio intrusion.

The same current data is used here to study the temporal and vertical structure variations of the semi-diurnal tidal current. A truncated Fourier transform was applied to each original velocity time series to remove fluctuations outside of the semi-diurnal tidal frequency band. The frequency bandwidth was $6.60 \times 10^{-3}$ cycle per hour (cph) and was centered at $8.05 \times 10^{-2} \mathrm{cph}$. Figures $3 \mathrm{a}$ and $3 \mathrm{~b}$ show a representative band-pass filtered velocity time series at $30 \mathrm{~m}, 80 \mathrm{~m}, 130 \mathrm{~m}, 180 \mathrm{~m}$ and $230 \mathrm{~m}$ for the east component velocity, $\mathrm{U}$, and the north component velocity, $\mathrm{V}$, respectively. The variation of the tidal current in the upper ocean showed different characteristics before and after the middle of October, coinciding with the Kuroshio intrusion. The $\mathrm{U}$ component had a smaller amplitude in the upper water column than in the lower one before mid-October, but then, the U component amplitude was nearly constant over the entire water column. This vertical distribution suggests that more than a single mode dominated in $\mathrm{U}$ before mid-October, but a barotropic tide dominated thereafter. The $\mathrm{V}$ component also showed a different vertical structure before and after the middle of October. Before mid-October, the amplitude of $\mathrm{V}$ was smallest in the upper ocean and increased generally with depth. Afterward, the amplitude was smallest at mid-depth and increased with distance from that depth in both directions. Such vertical distribution indicates that a mixed tidal mode and a first baroclinic tide were respectively important before and after mid-October. The Kuroshio intrusion thus appeared to had a significant impact on the 


\section{LOW FREQUENCY CURRENT STICK DIGRAM}

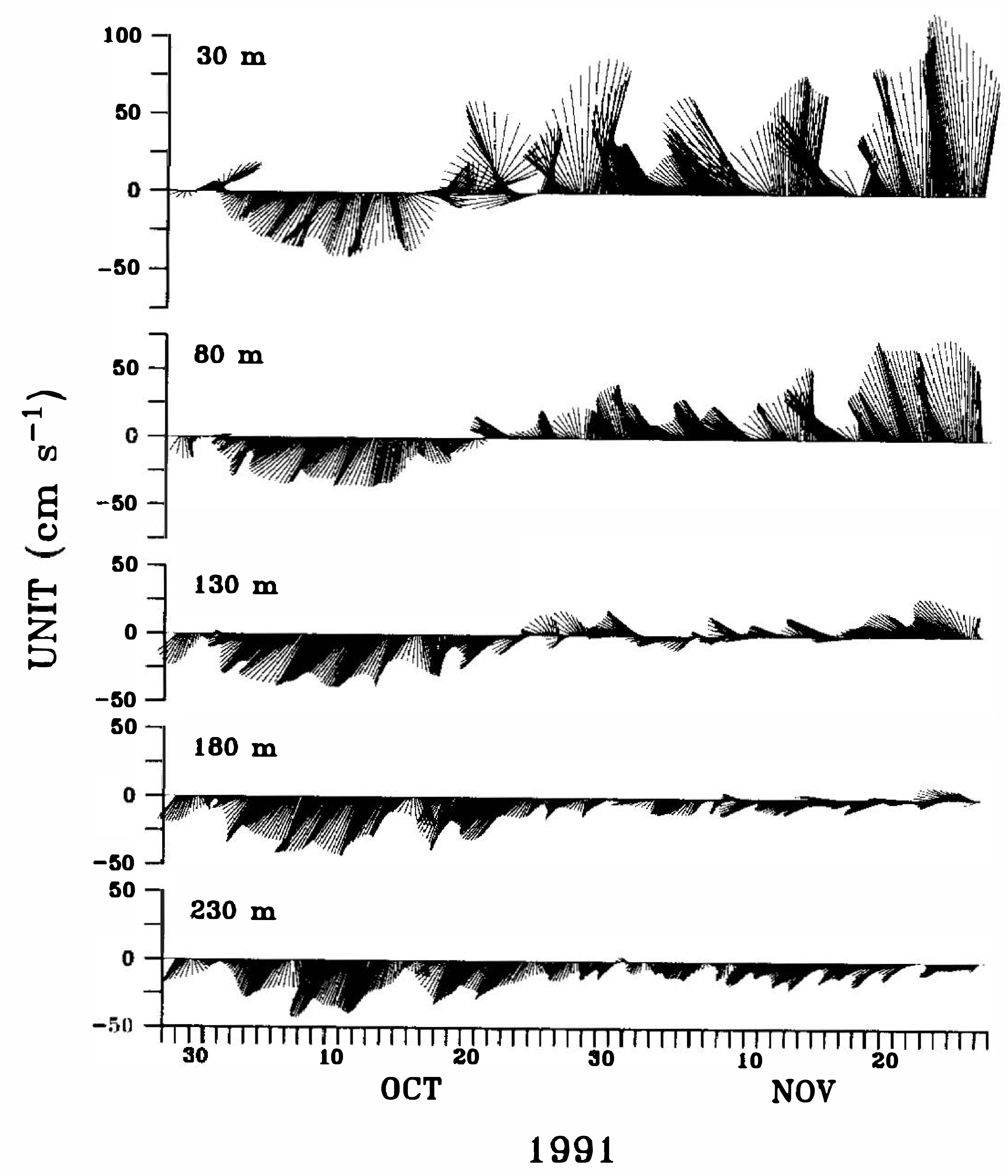

Fig. 2. Stick diagram of (36-hour) low-pass filtered current velocity at $30 \mathrm{~m}, 80$ $\mathrm{m}, 130 \mathrm{~m}, 180 \mathrm{~m}$ and $230 \mathrm{~m}$, respectively. Each stick indicates current direction and amplitude.

semi-diurnal tidal current. In addition to the spatial variation, the semi-diurnal tidal current also showed a temporal variation (oscillation) of nearly 2 weeks, apparently related to the neap and spring tides.

In order to study the variation of the vertical structure of the semi-diurnal tidal current before and after the intrusion of the Kuroshio, the original time series was divided into three segments. A similar method was used by Weisberg et al. (1987) to study the $M_{2}$ tidal current variation on the equatorial Pacific Ocean. The length of each segment was 456 hours (19 days). Segment I was from 9/29 to 10/17, Segment II was from 10/18 to 11/15, and Segment III was from 11/6 to 11/24. Segment I represented the tidal current before the intrusion, while Segments II and III represented it after the intrusion. A rotary spectra was applied to calculate the hodograph ellipse centered upon the $M_{2}$ tidal frequency at each of the 22 depths for the three segments. These ellipses are shown in Figure 4. Each column indicates the ellipses over the water column between $30 \mathrm{~m}$ and $240 \mathrm{~m}$ in each segment. The tidal ellipse was the largest in Segment II. In the lower water column (deeper than $140 \mathrm{~m}$ ), the ellipses did not change notably with time. Their orientations, sizes and senses of rotation 


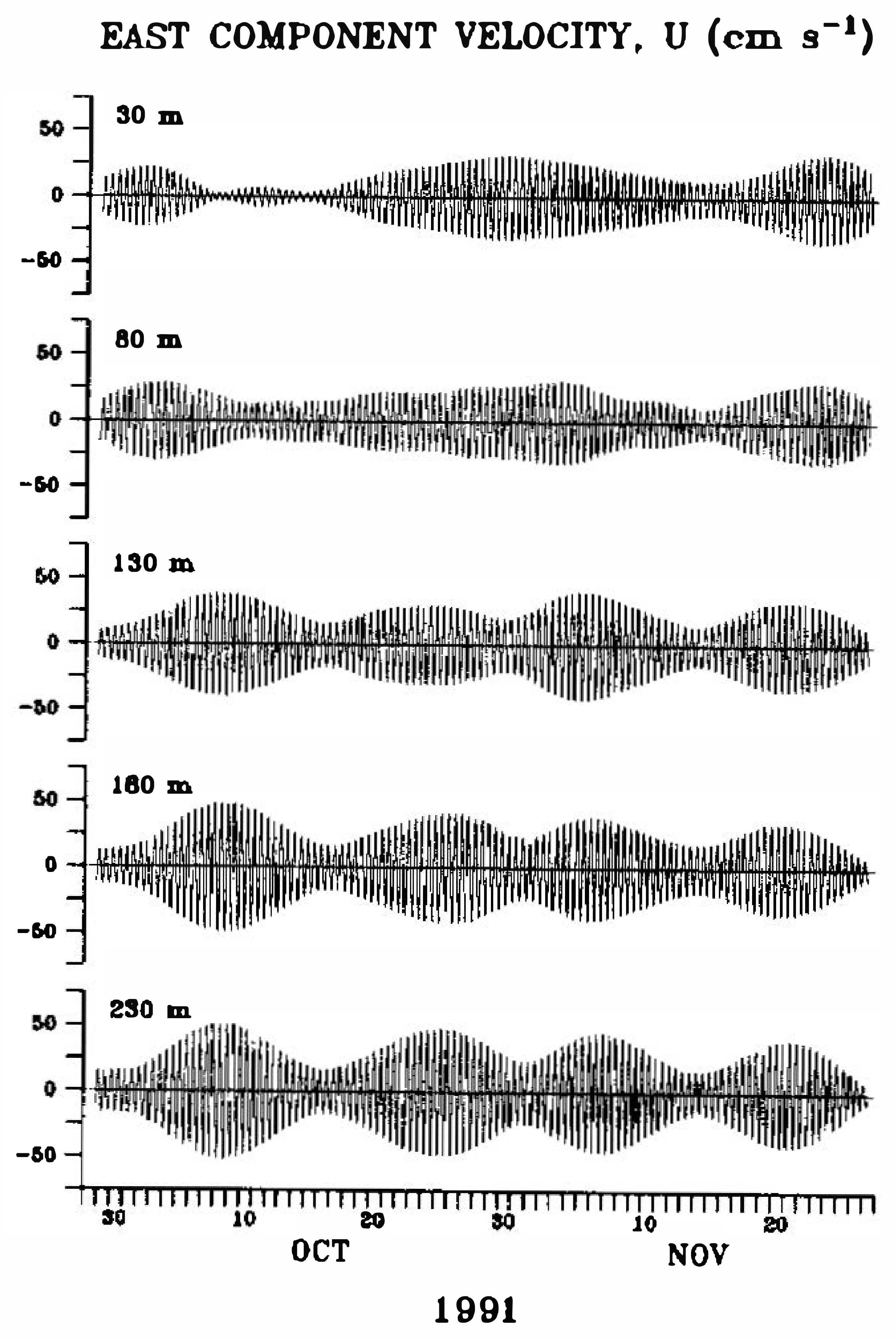

(a)

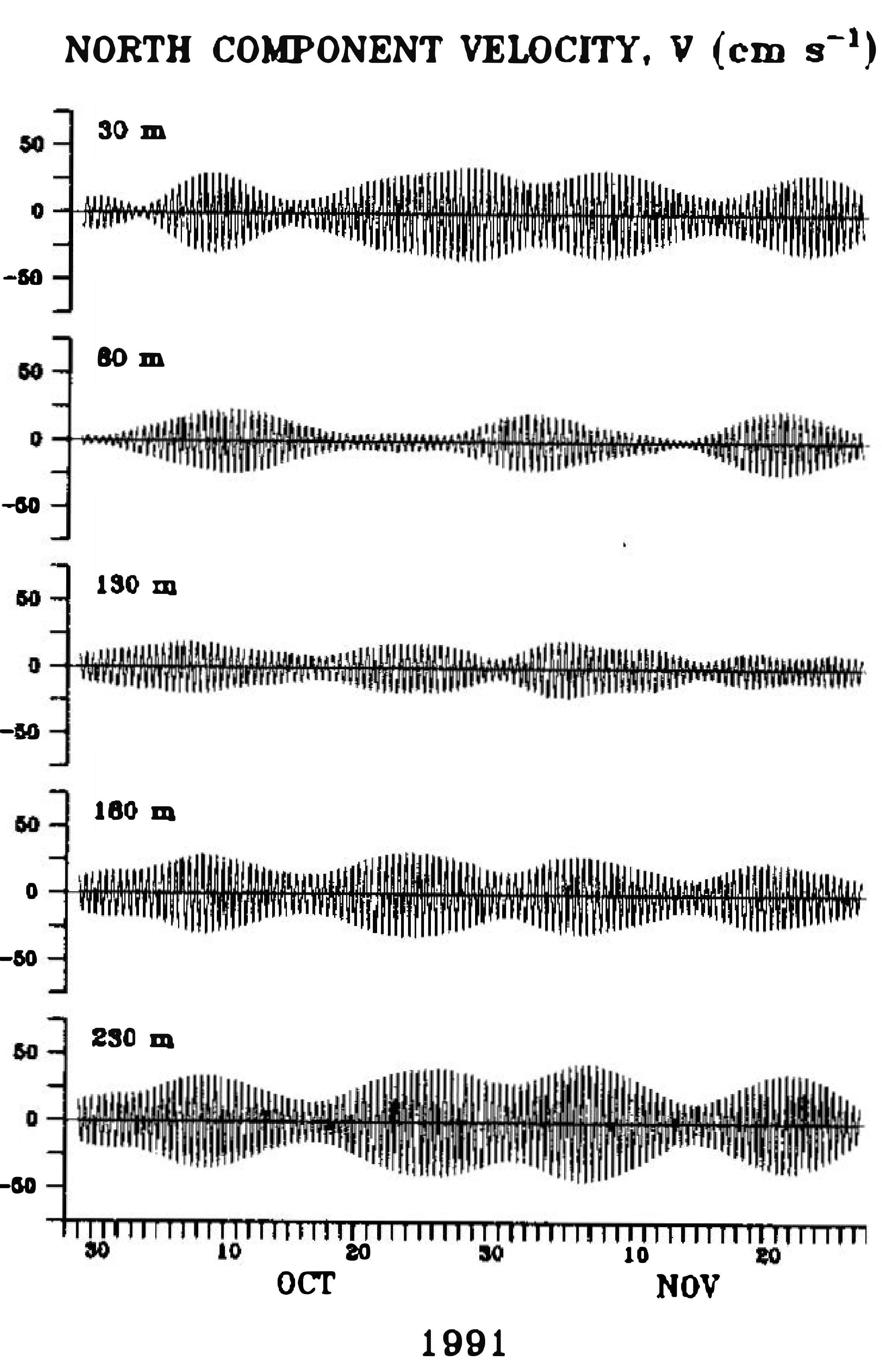

(b)

Fig. 3. (a) The band-passed filtered east component velocity (U) time series. The uppermost to the bottom panels show the $U$ at $30 \mathrm{~m}, 80 \mathrm{~m}, 130 \mathrm{~m}, 180$ $\mathrm{m}$ and $230 \mathrm{~m}$, respectively. (b) The band-passed filtered north component velocity $(\mathrm{V})$ time series. The uppermost to the bottom panels show the $\mathrm{V}$ at $30 \mathrm{~m}, 80 \mathrm{~m}, 130 \mathrm{~m}, 180 \mathrm{~m}$ and $230 \mathrm{~m}$, respectively.

were the same over the three segments. The amplitude of ellipse generally increased with depth. The orientation (around $0.75 \pi$ ) and the sense of rotation (clockwise) were consistent with depth. In contrast with those in the lower water column, the ellipses in the upper water column did vary with time. The ellipse orientation in Segment I varied anti-clockwise with depth from the uppermost depth to around $60 \mathrm{~m}$. Below that, the major elliptical axis was directed NW-SE. Unlike the ones in Segment I, the orientations of the ellipses in Segments II and III did not vary with depth in the upper ocean but abruptly changed at mid-depth and rotated clockwise around $\pi / 2$ at around $110 \mathrm{~m}$, where the size of the ellipse was the smallest. Below or above this mid-depth, the size of the ellipse increased with distance. This vertical distribution of tidal ellipses in Segments II and III was similar to the vertical structure of the first baroclinic semi-diurnal tide.

\section{COHERENCE ANALYSIS}

The coherence-squared and phase between tidal current velocities were calculated over all depth pairs in each segment. The central frequency and bandwidth used in the calculation were $8.05 \times 10^{-2} \mathrm{cph}$ and $6.6 \times 10^{-3} \mathrm{cph}$, respectively. The number of degree of freedom was 13 and the corresponding $90 \%$ significance level for the null hypothesis on coherencesquared was 0.35 . 


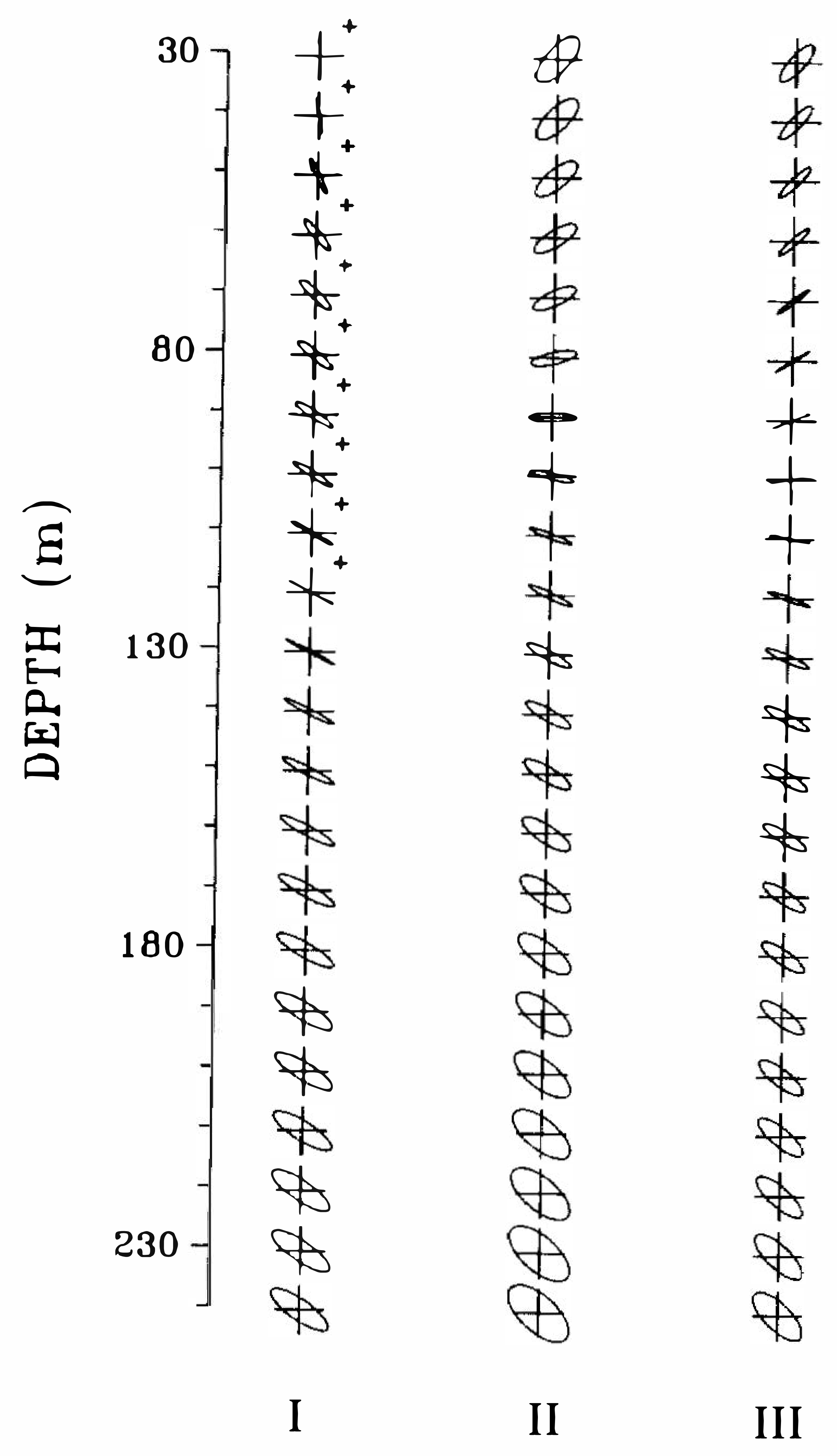

Fig. 4. The semi-diurnal tidal ellipses at each of 22 depths from $30 \mathrm{~m}$ to $240 \mathrm{~m}$ for Segments I, II and III. With the exception of those mark with a plus sign, all of the ellipses are polarized clockwise.

Figures 5 to 7 show the coherence-squared and phase between the $\mathrm{U}$ components over all depth pairs as a function of depth for the three segments. In Segment I, the coherencesquared values decreased with the distance between two depths in the upper water column and were high in the lower water column. There was incoherence between the upper and lower water columns and the phase lag was small over the whole. Unlike that in Segment I, the U components in Segments II and III were highly coherent over the whole water column. The phase lag increased with distance between two depths. The maximum phase lag, between the uppermost and bottom depths, was around $-\pi / 2$. In Segment I, results from the coherence analysis did not indicate any single mode predominating in $\mathrm{U}$, thus, a mixed tidal mode must be considered. Although the high coherence-squared values over the entire water column in Segments II and III suggest that a barotropic semi-diurnal tide dominated in $\mathrm{U}$, their corresponding phase distribution did not support such a hypothesis. Again, a mixed tidal mode was indicated.

The coherence-squared and phase between the $\mathrm{V}$ components over all depth pairs as a function of depth for the three segments are shown in Figures 8 to 10, respectively. In 

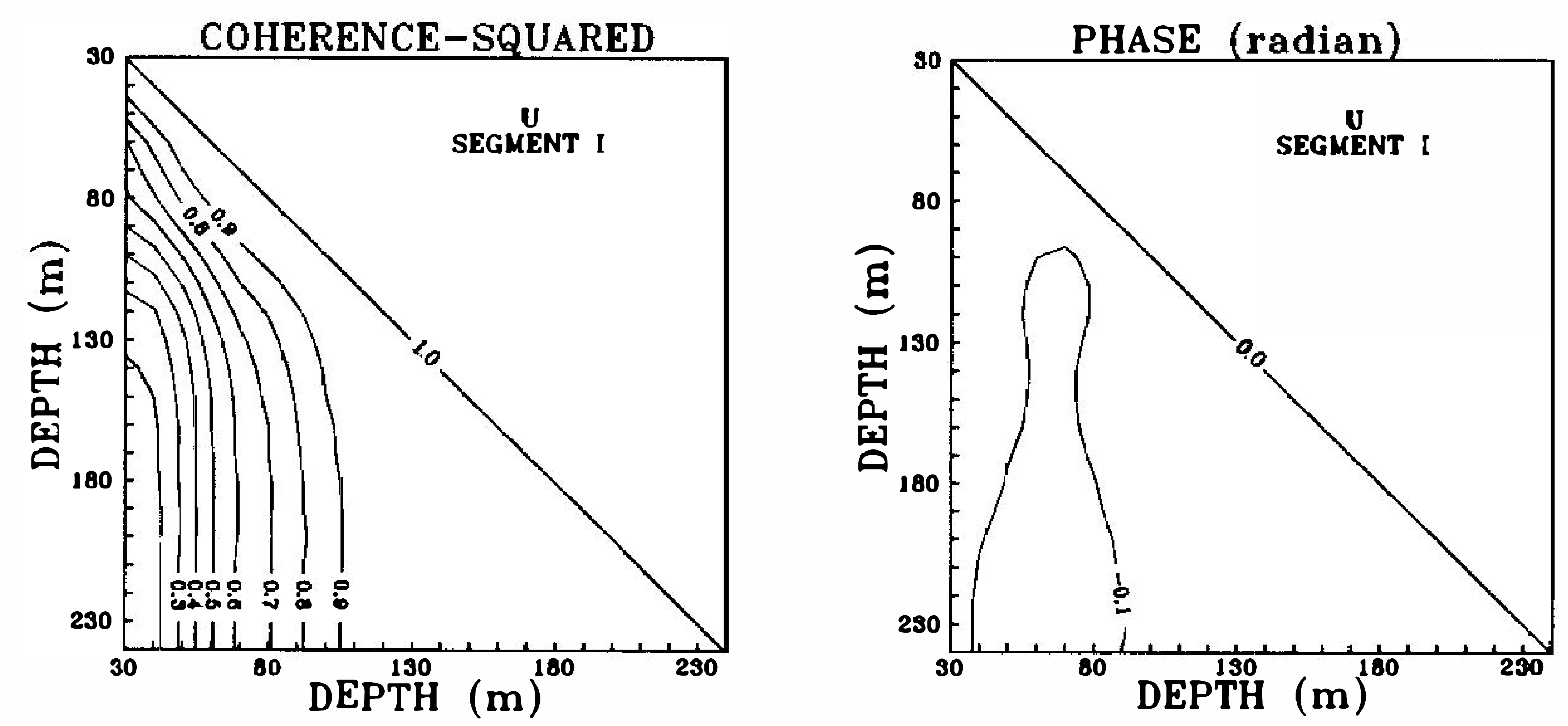

Fig. 5. Coherence-squared (left panel) and phase (right panel) between east components of velocity in Segment I, calculated over all depth pairs between $30 \mathrm{~m}$ and $240 \mathrm{~m}$.
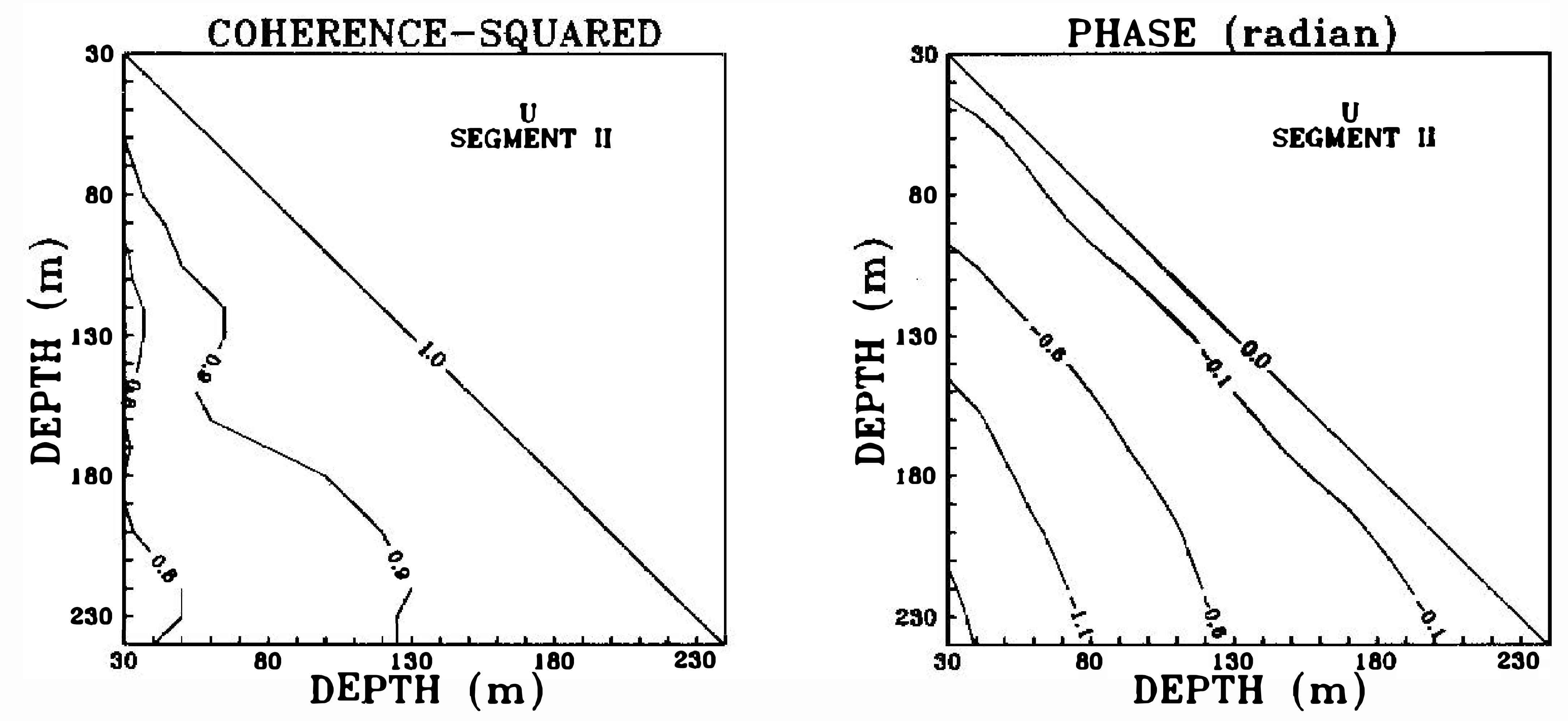

Fig. 6. Coherence-squared (left panel) and phase (right panel) between east components of velocity in Segment II, calculated over all depth pairs between $30 \mathrm{~m}$ and $240 \mathrm{~m}$.
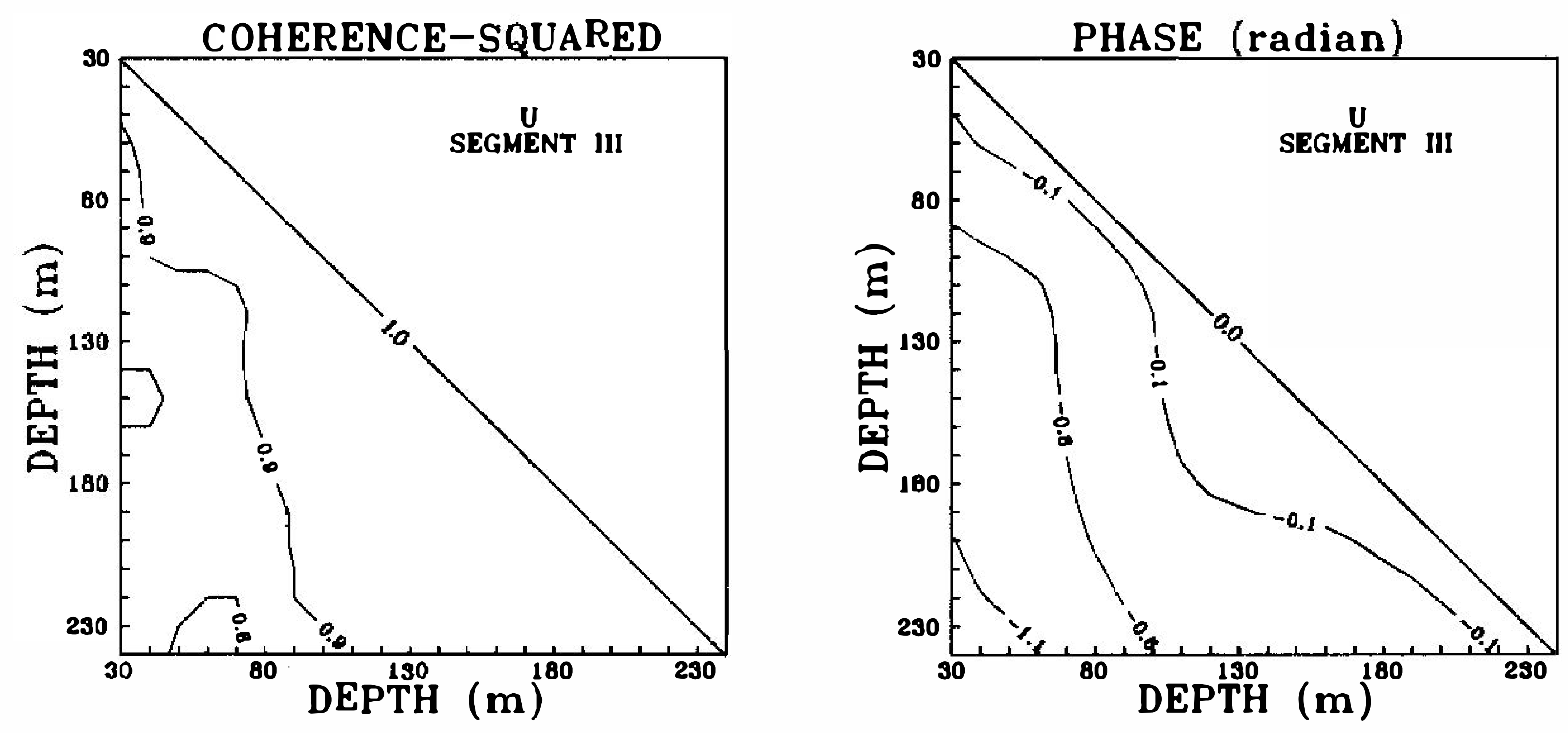

Fig. 7. Coherence-squared (left panel) and phase (right panel) between east components of velocity in Segment III, calculated over all depth pairs between $30 \mathrm{~m}$ and $240 \mathrm{~m}$. 

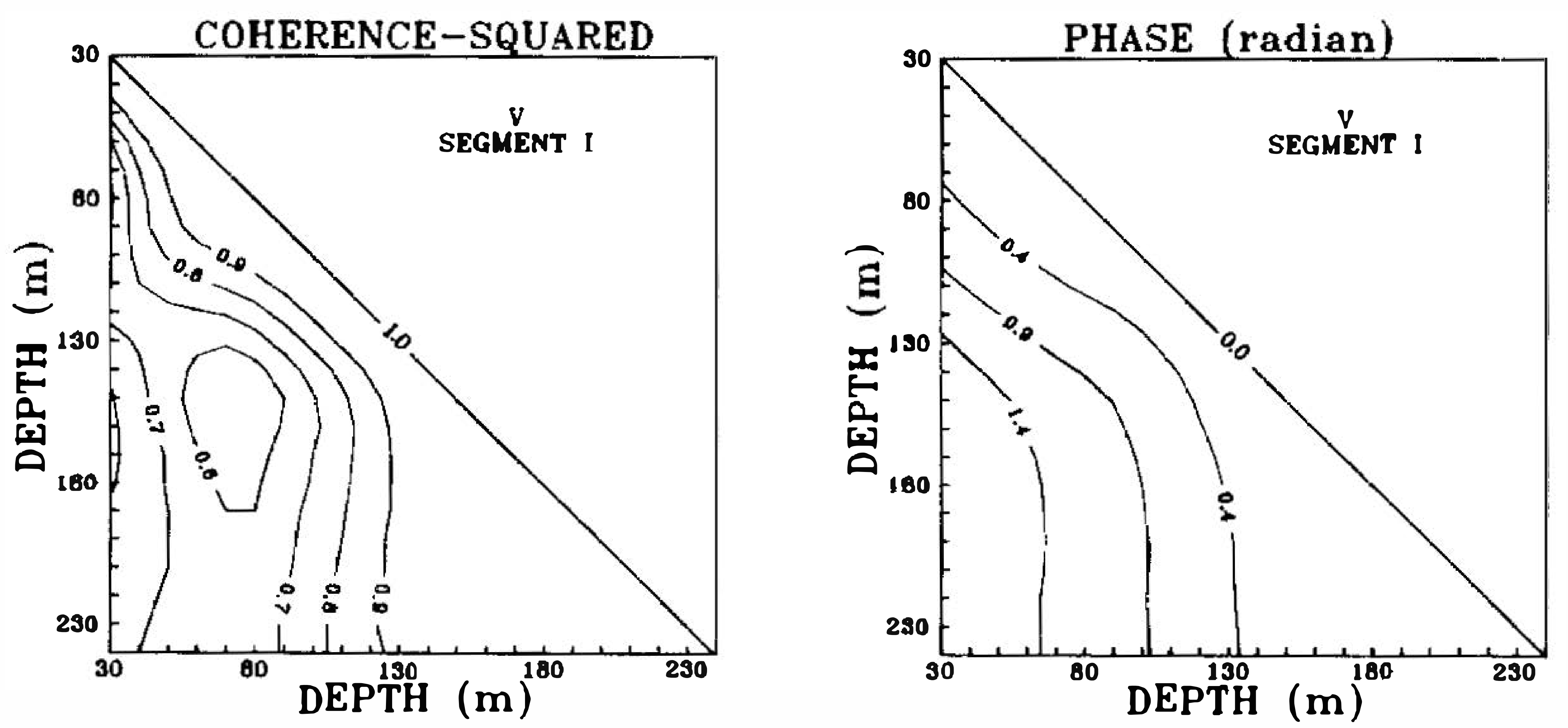

Fig. 8. Coherence-squared (left panel) and phase (right panel) between north components of velocity in Segment I, calculated over all depth pairs between $30 \mathrm{~m}$ and $240 \mathrm{~m}$.
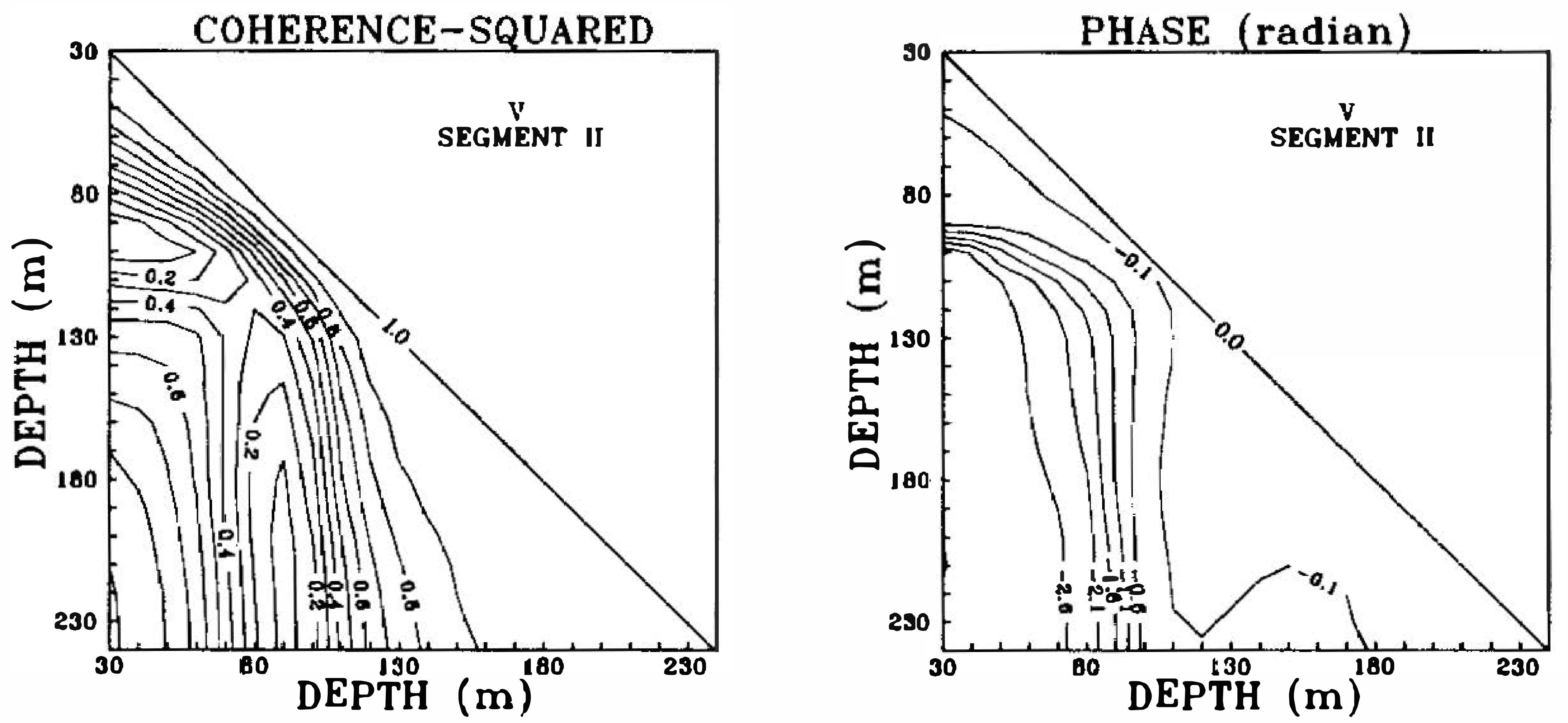

Fig. 9. Coherence-squared (left panel) and phase (right panel) between north components of velocity in Segment II, calculated over all depth pairs between $30 \mathrm{~m}$ and $240 \mathrm{~m}$.
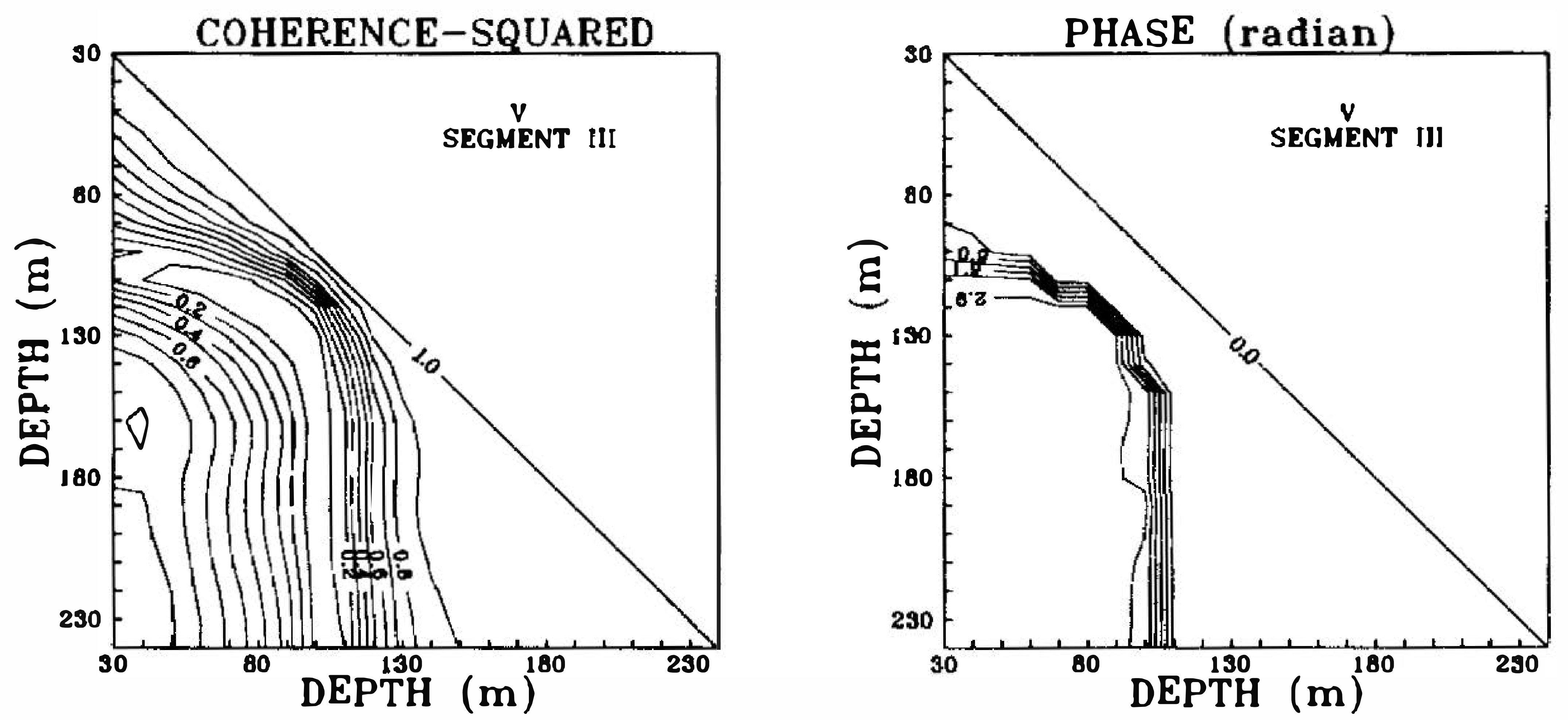

Fig. 10. Coherence-squared (left panel) and phase (right panel) between north components of velocity in Segment III, calculated over all depth pairs between $30 \mathrm{~m}$ and $240 \mathrm{~m}$. 
Segment I, a minimum value of coherence-squared was found around $80 \mathrm{~m}$. Below or above this depth, the coherence-square values were high. The phase lag increased with distance between depths in the upper $140 \mathrm{~m}$ of the water column. Below $140 \mathrm{~m}$, the $\mathrm{V}$ components were generally in-phase. Between the uppermost and bottom depths, the phase lag was $\pi / 2$. The distributions of coherence-squared and phase in Segments II and III were similar. Near $100 \mathrm{~m}$, the value of the coherence-squared was smallest, and the phase changed rapidly. The $\mathrm{V}$ components were coherent and in-phase in the water column below or above $100 \mathrm{~m}$. Between the upper and lower water columns, the $\mathrm{V}$ components were coherent but out-ofphase. The distribution of coherence-squared in Segment I was similar to those in Segments II and III, but the phase distributions were different. No single dynamic tidal mode was suggested in Segment I, and at least two tidal modes must be used to explain its vertical structure. The vertical distributions of coherence-squared and phase in Segments II and III, however, clearly indicated a first baroclinic tide dominating $\mathrm{V}$ with a nodal point near 100 m.

Coherence analysis indicated that both barotropic and first baroclinic tides are important. The Kuroshio intrusion had a significant impact on the vertical structure of the tidal current. After the intrusion, the first baroclinic tide was much more visible in both $\mathrm{U}$ and $\mathrm{V}$. Its nodal point was located around $100 \mathrm{~m}$. This result is similar to that found in the tidal ellipse analysis.

\section{BAROTROPIC AND BAROCLINIC TIDES}

The assumption that the vertical integration of baroclinic velocity over the water column between $30 \mathrm{~m}$ and $240 \mathrm{~m}$ is zero was applied in treating the depth average of $\mathrm{U}$ and $\mathrm{V}$ as the barotropic velocity. A similar method had been applied in a number of studies (Rosenfeld and Beardsley, 1987; Siedler and Paul, 1991). The potential error due to this assumption is discussed in the next section. The resultant barotropic hodograph ellipses for the three segments are shown in Figure 11. Although the semi-major axes and orientations of the barotropic tidal ellipses in the three segments had very similar values, they were still slightly different after the intrusion of the Kuroshio. Table 1 shows the values of the semi-major axes, orientation and phase lag between $U$ and $\mathrm{V}$. Before the intrusion, the amplitudes of $\mathrm{U}$ and $\mathrm{V}$ were comparable. The minor axis value was smallest in Segment I, since the phase lag between $U$ and $V$ was close to one $\pi$. The orientation rotated from about $0.8 \pi$ in Segment $I$ to $0.9 \pi$ in Segment III, meaning that the barotropic tidal current in $\mathrm{V}$ was reduced after the intrusion.

UNIT: $\left(\mathrm{cm} \mathrm{s}^{-1}\right)$

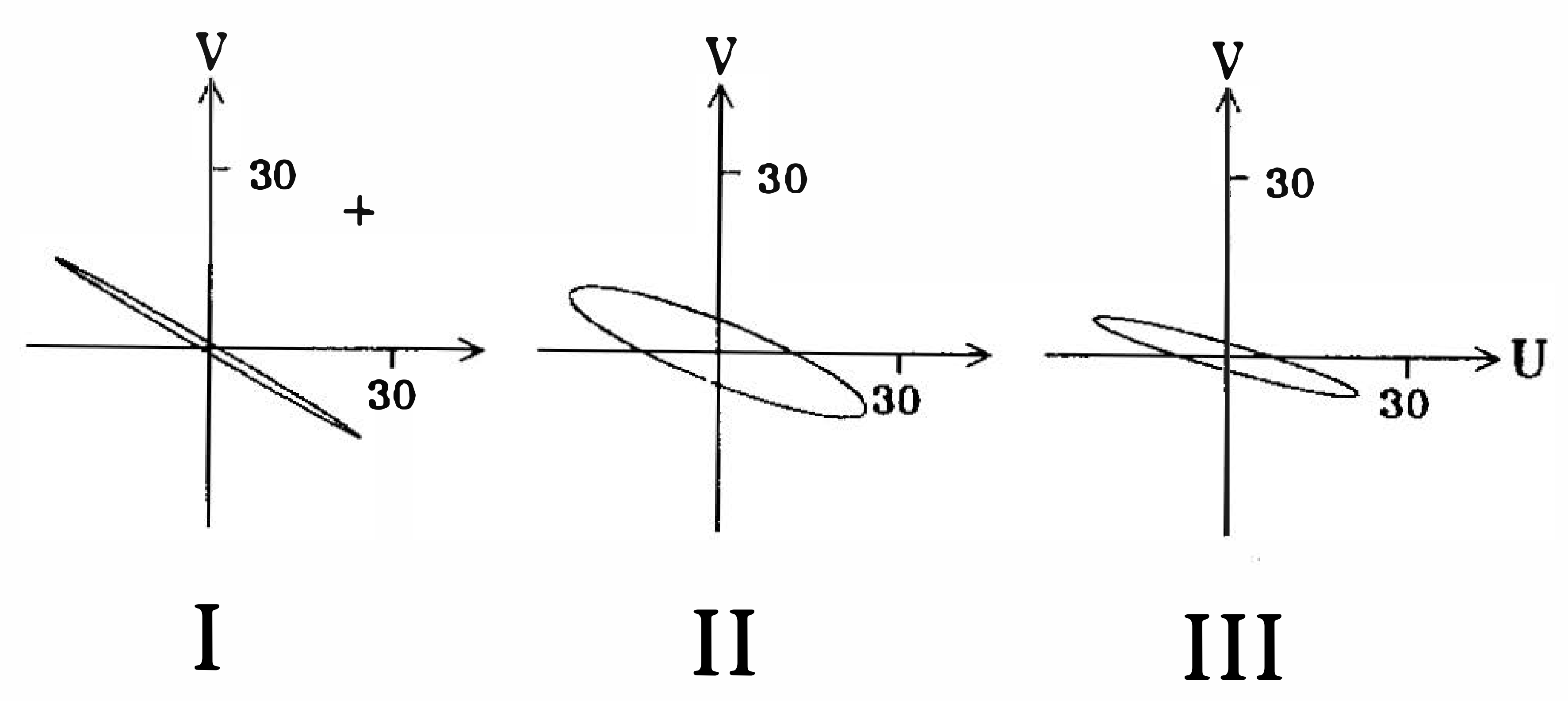

Fig. 11. The barotropic tidal ellipses in Segments I, II, III. The ellipse of Segment I, mark with a plus sign, is polarized anti-clockwise. 
Table 1. The semi-major axis, orientation and phase lag between the U and V components of the barotropic tidal ellipses in Segments I, II and III.

\begin{tabular}{lccc}
\hline Segment & I & II & III \\
\hline Amplitude $\left(\mathrm{cm} \mathrm{s}^{-1}\right)$ & 29 & 26 & 23 \\
Orientation $(\pi)$ & $\mathbf{0 . 8 3}$ & $\mathbf{0 . 8 8}$ & $\mathbf{0 . 9 1}$ \\
Phase $(\pi)$ & $\mathbf{0 . 9 8}$ & $\mathbf{0 . 8 2}$ & $\mathbf{0 . 8 8}$ \\
\hline
\end{tabular}

To subtract the depth average velocity from $U$ and $V$ at each depth, the residual velocity time series was treated as the baroclinic tidal current whose hodograph ellipses are shown in Figure 12. The influence of the Kuroshio intrusion is easily seen in this figure. After the intrusion, the ellipse was enlarged and its orientation changed from about $0.75 \pi$ to $0.5 \pi$. The amplitude of $\mathrm{V}$ increased significantly and was larger than the amplitude of U. Although the ellipse at each depth did show visible change after the intrusion, its vertical structure remained nearly the same. In all three segments, the ellipses were smallest at mid-depth (around $110 \mathrm{~m}-130 \mathrm{~m}$ ) but increased with the distance from that depth. The largest ellipses occurred both at the uppermost and bottom depths. The orientation varied rapidly at middepth (around $110 \mathrm{~m}-130 \mathrm{~m}$ ). Such a vertical structure indicated that a first baroclinic mode was dominant in the residual velocity field.

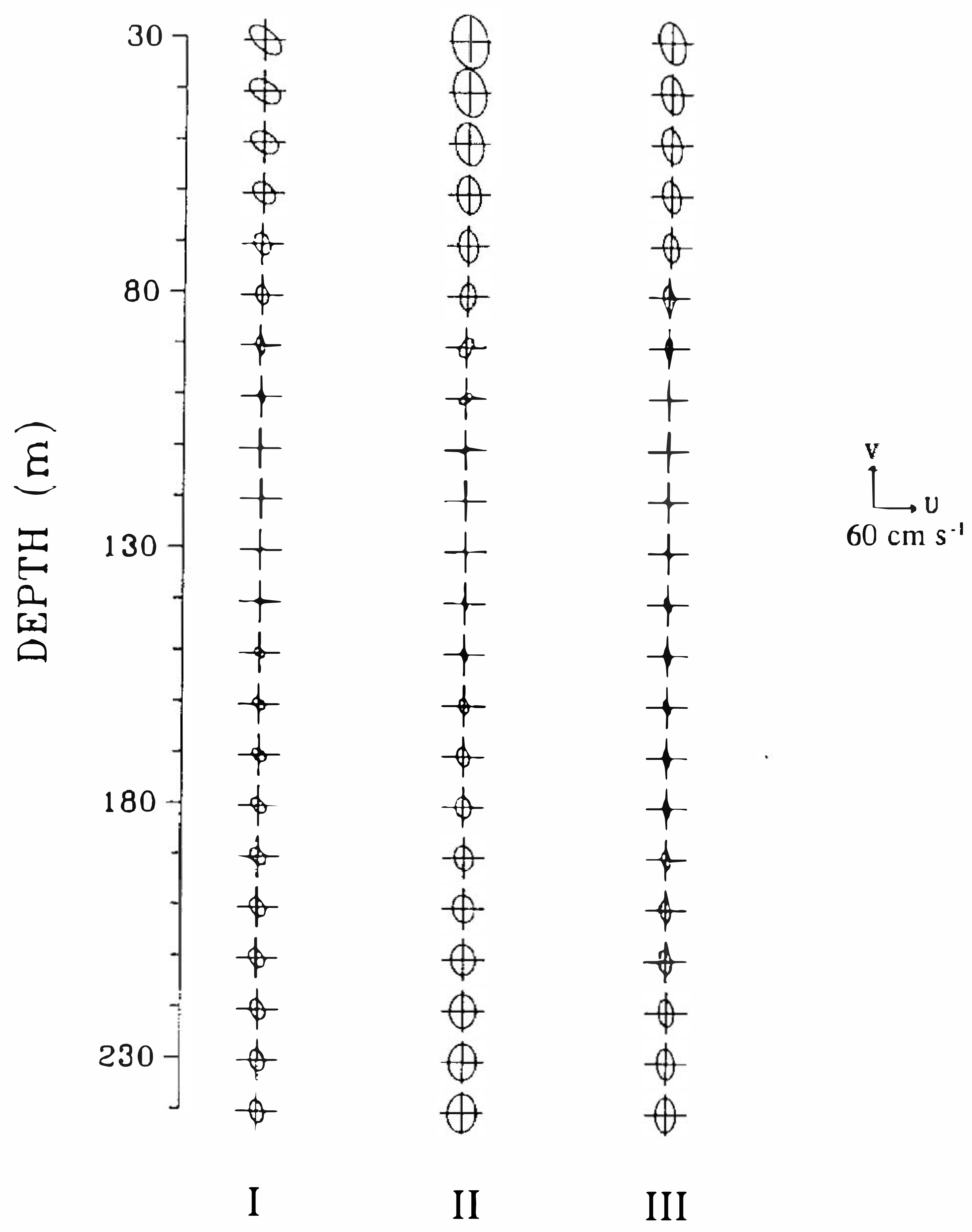

Fig. 12. The baroclinic tidal ellipses at each of 22 depths between $30 \mathrm{~m}$ and $240 \mathrm{~m}$ in Segments I, II and III. All of the ellipses are polarized clockwise. 
To further examine the vertical structure, a frequency domain Empirical Orthogonal Functions (EOF) was used to decompose the residual $\mathrm{U}$ and $\mathrm{V}$ separately into a set of orthogonal EOF modes (Wallace and Dickinson, 1972). The same central frequency and bandwidth were used. Cross-spectral matrices were constructed and their eigenvalues and eigenfunctions were calculated. The eigenvalues partition variance in orthogonal modes and the eigenfunctions give the spatial distribution of amplitude and phase for each mode (Tang et al., 1988).

In all three segments, the first EOF mode for both $\mathrm{U}$ and $\mathrm{V}$ contained over $90 \%$ of variance. Their vertical structures were also similar, indicating that only one mode was important. Figure 13 shows the vertical distributions of amplitude and phase for these six first mode eigenfunctions. The smallest amplitude was around $110 \mathrm{~m}-130 \mathrm{~m}$, where the phase changed rapidly. There was no phase difference in the water column above or below the middepths. The phase difference between these two sections of the water column, however, was $\pi$. A first baroclinic mode was obviously responsible for this vertical structure. The first EOF mode, which contained over $90 \%$ of variance, therefore, represented the first baroclinic mode. The baroclinic tidal current in $\mathrm{V}$ was enlarged significantly after the Kuroshio intrusion.
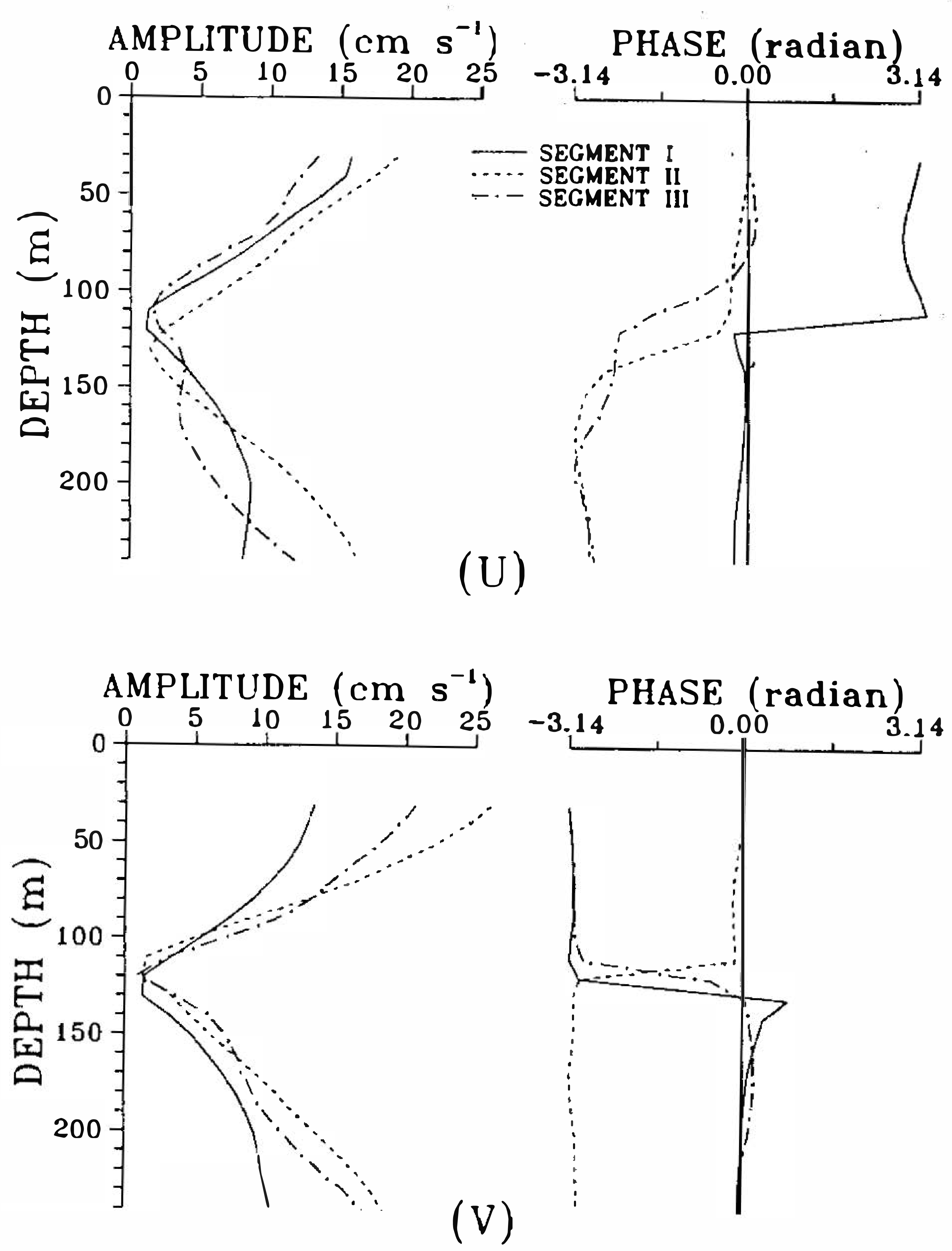

Fig. 13. The distribution of amplitude (left panels) and phase (right panels) for the first eigenfunction, calculated from the residual velocity time series. The upper two panels are for east component velocity, and the lower two panels are for north component velocity. The solid line represents Segment I, the dashed line Segment II, and the dashed-dotted line Segment III. 


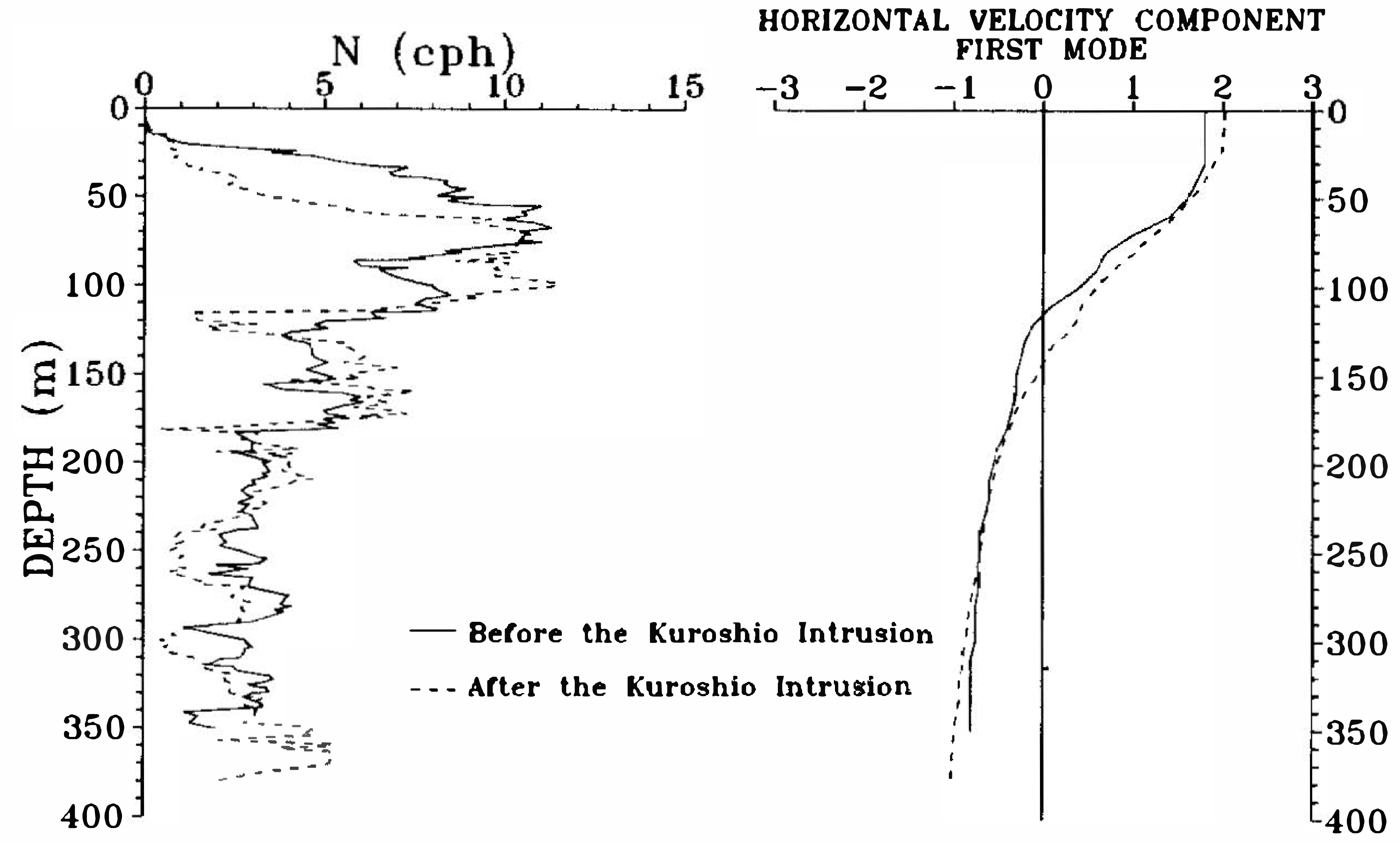

Fig. 14. The vertical distribution of $N$ (left) and the horizontal velocities of the first baroclinic mode (right) before and after the Kuroshio intrusion. The solid and dashed lines represent the results before and after the intrusion. The $N$ profiles were calculated by using CTD casts measured on 28th September (solid line) and 27th November (dashed line), 1991.

It is concluded that both the barotropic and first baroclinic tides were important in this area. The barotropic tidal current had a larger amplitude in $U$, while the baroclinic tidal current had a larger amplitude in $\mathrm{V}$. The nodal point of the first baroclinic tidal current was around $110 \mathrm{~m}-130 \mathrm{~m}$. After the Kuroshio intruded, the first baroclinic tide was enlarged, especially in $\mathrm{V}$, but its vertical structure did not show a significant change. The barotropic tide was slightly different. The amplitude of $\mathrm{V}$ was reduced, and the phase between $\mathrm{U}$ and $\mathrm{V}$ changed.

\section{DISCUSSION}

By assuming that tidal motions are linear, hydrostatic, viscid, and Boussinesq approximations, the governing equation for the vertical velocity $w$ on an $f$ plane (Roberts, 1975) is:

$$
\left[f^{2}+\frac{\partial^{2}}{\partial t^{2}}\right] w_{z z}+N^{2}\left[\frac{\partial^{2}}{\partial x^{2}}+\frac{\partial^{2}}{\partial y^{2}}\right] w=0
$$

where $x, y$ and $z$ are the east, north and vertical directions, respectively, while $f$ is the inertial frequency. If $N$, buoyancy frequency, is a function of $z$ only, the above equation can be separated into two others. One is a function of $x, y$ and $t$, while the other is a function of $z$ only. The latter can be written as:

$$
\tilde{w}_{z z}+\left[N(z) \lambda_{n}\right]^{2} \tilde{w}=0,
$$

where $\tilde{w}$ is a function of $z$.only, and $\lambda_{n}$ is a separation constant (eigenvalue). This equation can be solved numerically by imposing a rigid lid surface boundary and a flat rigid bottom 
boundary, with no flow penetrating into the flat bottom. The solution is the stin of a set af orthogonal dynamical modes, with each one corresponding to an eigenvalue which can be expressed as:

$$
\lambda_{n}^{2}=\frac{K_{n}^{2}}{\omega^{2}-f^{2}},
$$

where $K_{n}$ is the horizontal tidal wave number, and $\omega$ is the tidal frequency. By taking the derivative of $z$, the vertical structure of the horizontal velocity can be obtained. Figure 14 shows the vertical profiles of $N$ and the corresponding vertical structure of horizontal velocity for the first baroclinic mode, before and after the Kuroshio intrusion. The $N$ profiles were calculated by using CTD measurement casts after the mooring was done and then retrieved. A vertical convolution average was applied for smoothing. The computed nodal points of the first baroclinic mode before and after the intrusion were located at $115 \mathrm{~m}$ and $140 \mathrm{~m}$. This result agreed with previous findings, where the depth of nodal point was around $100-130 \mathrm{~m}$. It is noted that the depth of the nodal point descended $25 \mathrm{~m}$ after the Kuroshio intrusion occurred. A similar feature was found in the EOF result, but it was only seen in Segment II. By substituting the corresponding eigenvalue into Eq. (3), the first baroclinic tidal wave number was obtained. The relative phase and group velocities were also computed. The computed wavelength, phase velocities and group velocities before and after the intrusion were $54 \mathrm{~km}, 120 \mathrm{~cm} \mathrm{~s}^{-1}$ and $97 \mathrm{~cm} \mathrm{~s}^{-1}$ and $59 \mathrm{~km}, 132 \mathrm{~cm} \mathrm{~s}^{-1}$ and $107 \mathrm{~cm} \mathrm{~s}^{-1}$, respectively. This comparison shows only a small change among these physical characteristics before and after the intrusion of Kuroshio, which this small change was also found by considering the historical CTD measurements in the surrounding area of the ADCP mooring. The depth range of the nodal point of the calculated first baroclinic mode was $130 \pm 25 \mathrm{~m}$. The corresponding eigenvalues varied $\pm 13 \%$ from their mean. The conclusion, then, can be made that the depth of the nodal point of the first baroclinic mode, which was estimated directly from the current measurement, agrees with its theoretical value, which was calculated from the CTD measurement.

In section 4 , the barotropic tidal velocity was calculated by taking the vertical average of the current measurements over the water column between $30 \mathrm{~m}$ and $240 \mathrm{~m}$. Three assumptions were implicitly imposed on this calculation. The first was the rigid lid surface boundary condition $(u=0)$. The error due to this assumption is negligible. The second was the zero vertical velocity at bottom. Wunsch (1969) found that this assumption is likely applicable as long as the local bottom slope is also far from an apex. Although the bottom slope in here was not flat, it was far from an apex. The error due to this assumption should have therefore been negligible, too. To apply these two boundary conditions, the integration of the horizontal velocity of baroclinic tidal modes over the whole water column was assumed to be zero. Unfortunately, the present current measurement did not record the velocity over the whole water column, which meant the third assumption had to be applied. This assumption is that the incomplete vertical integration of horizontal baroclinic velocity was zero over the water column between $30 \mathrm{~m}$ and $240 \mathrm{~m}$, which is acceptable as long as the greater part of the water column is considered. To estimate the potential error owing to the third assumption, a residual velocity was computed by averaging the horizontal velocity between $30 \mathrm{~m}$ and 240 $\mathrm{m}$ from the calculated first baroclinic mode. Using the first baroclinic modes in Figure 14 as an example, the amplitudes of this residual velocity were equivalent to $8 \%$ and $13 \%$ of the first baroclinic velocity at $30 \mathrm{~m}$ before and after the Kuroshio intrusion. It could induce $18 \%$ 
of error on the barotropic tidal current or could shift the nodal point of the first baroclinic tidal current up or down by $20 \mathrm{~m}-30 \mathrm{~m}$. However, this amount of error would not have seriously distorted the characteristics of the semi-diurnal tide described above.

Magnell et al. (1980) studied the relationship between low-frequency current and the amplitude of the semi-diurnal tidal current at the sloping north edge of Georges Bank and found a nonlinear mechanism linking the tidal and low-frequency current. Likewise, the abrupt change in the low-frequency current in the present study area before and after the Kuroshio intrusion had a significant impact on the local tidal current.

\section{SUMMARY AND CONCLUSIONS}

In the present study, the vertical structure and temporal variation of the semi-diurnal tidal current on the shelf break northeast of Taiwan were examined. It was found that the vertical distribution of tidal current had different characteristics before and after the intrusion of the Kuroshio which occurred in mid-October (Tang and Yang, 1993). The observed velocity time series was divided into three segments, each one 19 days in length. The first segment contained the velocity series before the Kuroshio intruded, while the other two segments contained the velocity time series after the Kuroshio intrusion.

By examining the vertical distribution of tidal ellipses over the three segments, it was found in the present study that the tidal ellipses had similar characteristics in the lower water column but different in the upper water column before and after the intrusion of the Kuroshio. Before the Kuroshio intruded, Segment I varied slowly with depth from the uppermost to 60 $\mathrm{m}$. After the intrusion, in Segments II and III the orientation of tidal ellipse remained the same in the upper and lower water columns, but a rapid phase change was found at mid-depths, which in fact showed the smallest ellipse. These results indicate that the first baroclinic tide dominated after the Kuroshio intrusion. The calculated coherence values over all depth pairs indicated no single mode dominated the semi-diurnal tide in the $U$ component and suggested the first baroclinic tide was important in the V field, especially, after the intrusion. According to tidal ellipse and coherence analysis, the barotropic and first baroclinic modes were important in the studied area.

The barotropic tidal velocity was obtained by assuming that the vertical integration of the baroclinic tidal velocity between $30 \mathrm{~m}$ and $240 \mathrm{~m}$ was zero. The orientation and semimajor axis of the barotropic tide changed slightly over the three segments. The amplitude of the semi-major axis varied from around 29 to $24 \mathrm{~cm} \mathrm{~s}^{-1}$. Before the Kuroshio intrusion, the amplitudes of $\mathrm{U}$ and $\mathrm{V}$ were comparable with $\mathrm{V}$ decreasing after the intrusion.

The baroclinic tidal velocity was obtained by subtracting the barotropic tidal velocity from the original band-pass-filtered tidal velocity at each depth. The vertical structure of the baroclinic tidal ellipses were similar in the three segments. The smallest tidal ellipse was at around $110 \mathrm{~m}-130 \mathrm{~m}$, where the orientation changed rapidly. The baroclinic tidal ellipse had a similar vertical structure in each of the three segments, its orientation and size varied with time. The ellipses were smallest before the Kuroshio intrusion after which they enlarged. A frequency domain EOF was applied to further decompose the baroclinic tidal velocity time series. Only one EOF mode contained over $90 \%$ of variance in all three segments for both $\mathrm{U}$ and $\mathrm{V}$. The six first EOF modes had very similar vertical structures. The nodal point was at around $110 \mathrm{~m}-130 \mathrm{~m}$, which again was consistent with previous results.

The results from the above three different analytical methods were consistent. Both barotropic and first baroclinic tides were important on the shelf break northeast of Taiwan. 
The first baroclinic tide had its nodal point around $110 \mathrm{~m}-130 \mathrm{~m}$. Its vertical structure was generally stable with time, while its amplitude and phase changed after the Kuroshio intrusion. Before the intrusion, the barotropic and baroclinic tides were comparable, but afterwards, the baroclinic tide was enlarged and projected more energy onto its north component velocity. Combining changes in both barotropic and baroclinic components, the tidal current showed a different vertical distribution before and after the Kuroshio intrusion. The variation in local water stratification and low-frequency background current, induced by the intrusion of the Kuroshio, may have been responsible for the change in the semi-diurnal tidal current.

Acknowledgments The work described here is part of the Kuroshio Edge Exchange Process (KEEP) experiment, supported by the National Science Council of the Republic of China under grant NSC 83-0209-M-002A-009-K. Field work was performed aboard the R $\mathrm{V}$ Ocean Researcher I and the valuable assistance of the captain and his crew are appreciated. Mr. J. Donovan and W. T. Lue were responsible for the mooring installation and deployment. This manuscript benefited from the discussions with Mr. Y. J. Yang. The authors would like to thank Mr. S. M. Yang for his assistance with data retrieval and S. Liu for preparations for publication of the study.

\section{REFERENCES}

Baines, P. G., 1982: On internal tide generation models. Deep Sea. Res., 29, 307-338.

Baines, P. G., 1986: Internal tides, internal waves and near-inertia motion. In: C. N. K. (Ed.), Baroclinic Processes on Continental Shelves., Mooers, AGU, Washington, D. C., 19-31.

Chern, C. S., and J. Wang, 1990: On the mixing of waters at a northern offshore area of Taiwan. TAO, 1, 297-306.

Hayes, S. P., and D. Halpern, 1976: Observations of internal waves and coastal upwelling off the Oregon coast. J. Mar. Res., 34, 247-267.

Magnell, B. A., S. L. Spiegel, R. I. Scarlet, and J. B. Andrews, 1980: The relationship of tidal and low-frequency currents on the north slope of Georges Bank. J. Phys. Oceanogr., 10, $1200-1212$.

Maxworthy, T., 1979: A note on the internal solitary waves produced by tidal flow over a three-dimensional ridge. J. Geophys. Res., 84, 338-346.

Rattray, M., J. Dworski, and P. Kovala, 1969: Generation of long internal waves at the continental slope. Deep Sea Res., 16, 179-195.

Roberts, J, 1975: Internal gravity waves in the ocean. Marcel Dekker Inc. Press, 274pp.

Rosenfeld, L. K., 1990: Baroclinic semidiurnal tidal current over the continental shelf off northeast Califomia. J. Geophys. Res., 95, 22153-22172.

Rosenfeld, L. K., and R. C. Beardsley, 1987: Barotropic semidiurnal tidal currents off northern California during the Coastal Ocean Dynamics Experiment (CODE). J. Geophys. Res., 92, $1721-1732$.

Sandstorm, H., 1976: On the topographic generation and coupling of internal waves. Geophys. Fluid Dyn., 7, 231-271. 
Sherwin, T. J., 1988: Analysis of an internal tide observed on the Malin Shelf, north of Ireland. J. Phys. Oceanogr., 18, 1035-1060.

Siedler, G., and U. Paul, 1991: Barotropic and baroclinic tidal currents in the eastern basins of the north Atlantic. J. Geophys. Res., 96, 22259-22271.

Tang, T. Y., R. H. Weisberg, and D. Halpern, 1988: Vertical structure of low frequency variability in the eastern equatorial Pacific Ocean. J. Phys. Oceanog $r ., 18,1009-1019$.

Tang, T. Y., and Y. J. Yang, 1993: Low frequency current variability on the shelf break northeast of Taiwan. J. Oceanogr., 49, 193-210.

Wallace, J. M., and R. E. Dickinson, 1972: Empirical orthogonal representation of time series in the frequency domain. Part I: Theoretical considerations. J. Appl. Meteor., 11, 893-900.

Weisberg, R. H, D. Halpern, T. Y. Tang, and S. M. Hwang 1987: $M_{2}$ tidal currents in the eastern equatorial Pacific Ocean. J. Geophys. Res., 92, 3821-3826.

Wunsch, C., 1969: Progressive internal wave on slope. J. Fluid Mech., 35, 131-144.

Wunsch, C., 1975: Internal tides in the ocean. Rev. Geophys. Space Phy's., 13, 167-182.

Zeilon, N., 1912: On the seiches of the Gullmar Fjord. Sv. Hydrogr. Biol. Komm Skr., $5,1-49$. 